$5^{\text {TH INTERNATIONAL MULTIDISCIPLINARY }}$ SCIENTIFIC CONFERENCE ON SOCIAL SCIENCES \& ARTS SGEM 2018

CONFERENCE PROCEEDINGS VOLUME 5

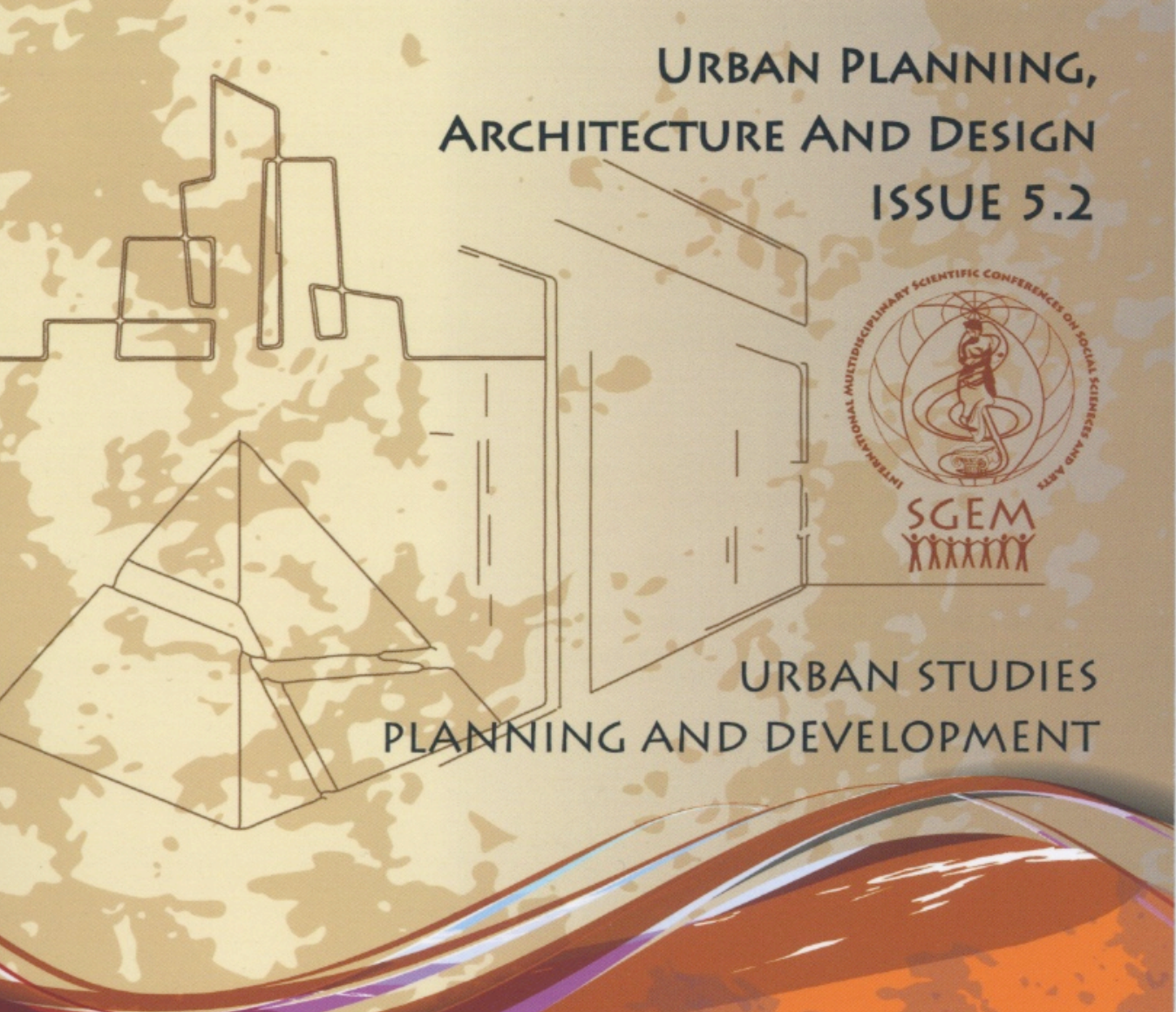


$5^{\text {th }}$ INTERNATIONAL MULTIDISCIPLINARY

SCIENTIFIC CONFERENCE ON SOCIAL SCIENCES AND ARTS S G E M 2018

CONFERENCE PROCEEDINGS

VOLUME 5

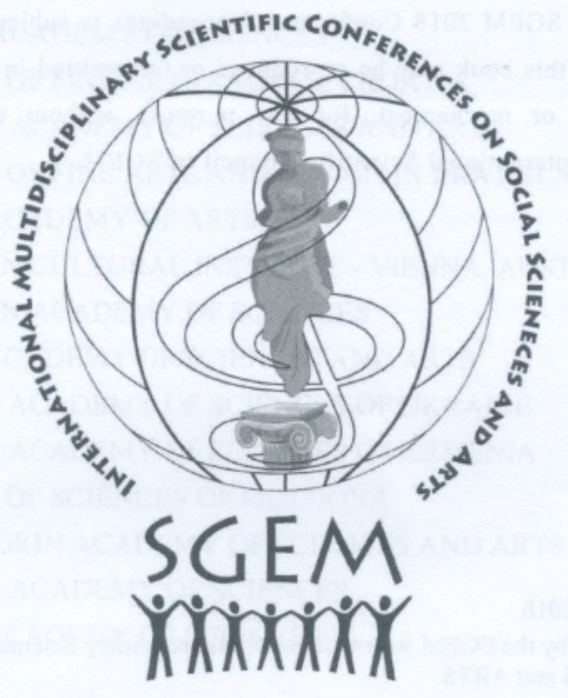

URBAN PLANNING, ARCHITECTURE \& DESIGN

ISSUE 5.2

URBAN STUDIES

PLANNING AND DEVELOPMENT

26 August - 01 September, 2018 Albena Co., Bulgaria 


\section{DISCLAIMER}

This book contains abstracts and complete papers approved by the Conference Review Committee. Authors are responsible for the content and accuracy,

Opinions expressed may not necessarily reflect the position of the International Scientific Council of SGEM.

Information in the SGEM 2018 Conference Proceedings is subject to change without notice. No part of this book may be reproduced or transmitted in any form or by any means, electronic or mechanical, for any purpose, without the express written permission of the International Scientific Council of SGEM.

Copyright (C) SGEM2018

All Rights Reserved by the SGEM International Multidisciplinary Scientific Conference on SOCIAL SCIENCES and ARTS

Published by STEF92 Technology Ltd., 51 "Alexander Malinov" Blvd., 1712 Sofia, Bulgaria Total print: 5000

ISBN 978-619-7408-60-7

ISSN 2367-5659

DOI: 10.5593/sgemsocial2018/5.2

SGEM INTERNATIONAL MULTIDISCIPLINARY SCIENTIFIC CONFERENCE ON SOCIAL SCIENCES AND ARTS

Secretariat Bureau

E-mail: sgem@sgemsocial.org

URL: www.sgemsocial.org 


\section{ORGANIZERS \& SCIENTIFIC PARTNERS}

- EUROPEAN ACADEMY OF SCIENCES, ARTS AND LETTERS

- THE CZECH ACADEMY OF SCIENCES

- POLISH ACADEMY OF SCIENCES

- SLOVAK ACADEMY OF SCIENCES

- SCIENCE COUNCIl OF JAPAN

- Russian ACADEMY OF SCIENCES

- LATVIAN ACADEMY OF SCIENCES

- aCADEMY OF Fine aRTS ZaGReb, CROATIA

- croatian aCADEMY of SCIENCES AND aRTS

- ACADEMY OF FINE ARTS AND DESIGN IN BRATISLAVA

- RUSSian aCADEMY of arts

- bulgarian CUltural inStitute - VienNa, AUSTRia

- bulgarian aCADEMy of SCIENCES

- SERBIAN ACADEMY OF SCIENCES AND ARTS

- NATIONAL ACADEMY OF SCIENCES OF UKRAINE

- NATIONAl ACADEMY OF SCIENCES OF ARMENIA

- aCADEMy of SCIENCES of moldova

- MONTENEGRIN ACADEMY OF SCIENCES AND ARTS

- georgian aCADEMy of SCIENCES

- TURKISH ACADEMY OF SCIENCES

\section{INTERNATIONAL SCIENTIFIC COMMITTEE}

\section{URBAN PLANNING, ARCHITECTURE \& DESIGN}

- Prof. Lidia Cristea, Romania

- Prof.dr. Petras Grecevičius, Lithuania

- Prof. dr. sc. Sanja Nikčević, Croatia

- Prof. Dr. Mark Meerovich, Russia

- Prof. Lucio Altarelli, Italy

- Prof. Dr-Arch. Sofia Letelier Parga, Chile

- Prof. David Bershad, Canada 
- Assoc. Prof. Eleni Lapidaki, Greece

- Assoc. prof. Malvina Russeva, Bulgaria 
53. IMPACT OF MINING ACTIVITIES AND NATURAL HAZARDS ON LAND USE: A CASE STUDY FROM SLOVAKIA, Jana Vojtekova, Matej Vojtek, Martin Boltiziar, Constantine The Philosopher University in Nitra, Slovakia..... 423

54. MANAGEMENT OF THE CONSTRUCTION PROCESSES OF PUBLIC WORKS IN ITALY, Alessandra Cucurnia, Universita degli Studi di Firenze, Italy. 431

55. MAPPING AND ASSESSMENT OF LAND USE CHANGES IN COAL MINING AREA: A CASE STUDY FROM SLOVAKIA, Matej Vojtek, Jana Vojtekova, Martin Boltiziar, Constantine The Philosopher University in Nitra, Slovakia.

56. PEOPLE'S PERCEPTION ON FLOOD RISK MANAGEMENT IN POLOG REGION, Agron Rustemi, South East European University, FYR of Macedonia .......447

57. PLANNING OF URBAN DEVELOPMENT: THE INFLUENCE OF MEGAEVENTS ON THE TRANSFORMATION OF URBAN ENVIRONMENT ELEMENTS (THE CASE OF YEKATERINBURG AS THE 2018 FIFA WORLD CUP HOST CITY), Alexandra Dmitrieva, Ekaterina Bugrova, Ural Federal University, Russia 455

58. RESIDENTIAL BUILDING DEVELOPMENT IN THE CONTEXT OF CREATING SPATIAL ORDER IN SUBURBAN AREAS, MSc Eng. Maciej Delnicki, Warsaw University of Technology - Faculty of Geodesy and Cartography, Poland. .463

59. RISK MANAGEMENT IN ENGINEERING ACTIVITIES - MATRIX METHOD AND MULTI-CRITERIA ANALYSIS, Szafranko Elzbieta, University of Warmia and Mazury in Olsztyn, Poland .471

60. SMART SPECIALIZATIONS AS INNOVATIVE ECOSYSTEMS., Elzbieta Wojnicka-Sycz, Piotr Sycz, Gdansk University of Technology Architecture Faculty, Poland

61. SPATIAL CHANGES IN THE HEALTH RESORTS OF SOUTHERN POLAND. BASED ON MUSZYNA ZDRYJ EXAMPLE., Wojciech Karol Wojcikowski, Cracow University of Technology, Poland ............................................487

62. SPATIAL POLICY VERSUS ADMINISTRATIVE DECISIONS. CASE STUDY: DEVELOPMENT OF THE AREA OF FORMER CLAY PITS AT JELONKI (WARSAW), PhD Wojciech Bartoszczuk, Warsaw University of Technology - Faculty of Geodesy and Cartography, Poland.

63. STRATEGIC ASPECTS IN SPATIAL PLANNING - THEORY AND PRACTICE IN LARGER CITIES OF POLAND, Assoc. Prof. Dr. Habil. Eng. Arch. Jacek Soltys, Gdansk University of Technology Architecture Faculty, Poland.............503 


\title{
MANAGEMENT OF THE CONSTRUCTION PROCESSES OF PUBLIC WORKS IN ITALY
}

\author{
Dr. Alessandra Cucurnia ${ }^{\prime}$ \\ ${ }^{1}$ Florence University, Italy
}

\begin{abstract}
Detailed assessments on the feasibility of a project help to define its implementation strategies, moreover mitigating its non-quality risks. As a formal guarantee of this principle, processes concerning the construction of public works in Italy consider an exante phase of the programme, which encompasses projects accompanied by feasibility checks of design alternatives. The latter, through technical, economic, managerial, etc., assessments, represents a decision-making support for the planning and design of individual projects, assuming the existence of public utility characteristics. Tools to support decision-making ex-ante seem to be highly important, above all in the case of strategic projects, understood as initiatives capable of producing social and economic development, competitiveness and the improvement of local resources.
\end{abstract}

The feasibility checks, enabling formalizations with different connotations and intensities, but fine-tuned according to the specific projects, represent key devices for the rational, efficient and economically sustainable management of the initiatives. They also mitigate the inevitability of the uncertainty scenarios characteristic of each initiative, and minimize their risks.

In terms of economic and financial sustainability, these checks concern whether the initiatives represent an opportunity or not in relation to the size, risks and implementation time. Moreover, they consider the identification of ways to:

- obtain financial resources:

- achieve the economic and financial balance of the investments, in relation to the expected revenues, and the time required to produce them, and the monetary flows that can be allocated in the construction phases as well as management and maintenance phases.

Critical scenario factors primarily converge in the weakness of the public client, in terms of the internalization of skills, moreover associated with the current phase of restrictions on available resources, which often translate into processes of delegation to other operators, not devoid of diseconomies, which can often be attributed to a lack of management and public scrutiny.

Keywords: regulations, building process, programming, design, reliability

\section{INTRODUCTION}

In Italy, the principles that inspire the rules governing the management of Public Works contracts [1], acknowledging the guidelines of EU directives, are aimed at conferring transparency and correctness to protect economic operators, to ensure greater guarantees for the Public Administration and to promote an appropriate use of the public funds. 
The survey on performance practices has shown that the effects produced by the decision-making positions, taken during the preliminary stages of the building process, are decisive for the entire realization process, also considering the importance assumed by the "circularity" that characterizes the process.

Therefore, in the realization system of Public Works, the programming instruments and the Technical and Economic Feasibility Design, which in the Italian legal system represents the first level of technical detail (Article 23, subsection 1 [1]) of the design process, are strategic devices for the purposes of the efficiency of procedural models, aimed at evading margins of interpretative discretion and, at the same time, at fighting the occurrence of discrepancies in the construction processes attributable to errors and shortcomings associated with the Design phase.

In order to protect the realization processes, the legislation provides for control mechanisms that, during the Design phase, are made explicit in the verification and validation procedures aimed at detecting and correcting design errors before the start of the construction stage.

These mechanisms impose binding administrative obligations, which attribute responsibility to the professionals, operating within the process, for the economic, administrative and possibly criminal consequences that could be derived from their potential non-compliance.

In the Construction phase, they translate into the consistency check of the work, in terms of performance, time and economic, with respect to the design specifications and the pursuit of a rational managerial organization, able to interface the different operators involved, facilitate the transferring information, supporting works implementation procedures.

\section{PROCESS PHASES}

The administration of Public Works is based on the definition of some key points of the process that, regardless of the different intervention models, are amounted as invariant elements to which precise attributions of activities, roles and responsibilities correspond. These elements refer to four segments associated with the Planning, Design, Construction and Management phases.

The purpose of the Planning is to make the requests of the client unambiguous; provide certainty about the needs to be met; produce a rough idea of the building organism to be built; provide reliable information on the necessary financial resources, on the operations to be performed and on their length, defining a corpus of information preparatory to the next phases.

The Design, through the acquisition of the data resulting from the programming period and the elaboration of technical and economic decisions, must provide an exhaustive definition of the intervention, optimizing the design solution in technical-constructive, functional, aesthetic and economic terms, in order to guarantee the highest quality, through a coherent response with the picture emerged during the Programming phase, so that the relationship between the client and the manufacturer is completely defined. 
In the Construction phase, intended as a final synthesis between design intentions and production realities, the procurement procedures are implemented, the realization stage is managed and verified that what has been built complies with the design instructions.

The Management phase is dedicated to supporting the operation of the building, maintaining, over time, the functionality of all its constituent elements.

According to this approach, the phases of the building process are configured as identifiable sequences of events, consisting of coherent activities, aimed at producing pre-established results that involve forms of technical transfer or delivery steps, and as such, in the moments preceding the transition between the development segments, must be verified through the continuous comparison with the program indications and approved in order to guarantee their completeness and suitability.

A further control activity, to guarantee the reliability of the final result, is represented by the testing of the works (Article 102 [1]) aimed at verifying the quality of the built product and its compliance with what has been planned in the Planning stage, defined in the Design step and materially realized in the Construction phase.

\section{PREPARATORY DOCUMENTS FOR DESIGN}

Within the individual segments of the process, the Planning phase, as an indispensable condition to start any building intervention that can be financed with public funds,
represents the cardinal point of Quality.

In order to ensure the consistency of the interventions to be carried out to the requirement of the community, to the needs of the client Administration and to the expectations of the end users, the Requirements Framework (Article 3, subsection 1, letter ggggg-nonies, provision introduced by Law 56/17 [2], and Article 23, subsection $3[1])$ is put together.

Before starting the creation processes of Public Works, the Administrations prepare a document that, according to the specific circumstances, identifies the needs to be satisfied, the general objectives to be achieved and the implementation methods to be
used.

The Requirements Framework, in line with the fundamental principle according to which there is not only one way of solving a problem but a varied range of possible alternatives, represents the parameterization necessary to define, if the conditions exist, the possible competing interventions motivated by the need for satisfy the findings,

In order to achieve effective development strategies and acquire reliable projects, the Administrations also draw up the Guidance Design Document (Article 3, subsection 4 [5]) which represents the operational tool for the subsequent development of the process. It is a document that summarizes all the activities and programs them in details regarding timing, sequence, responsibility, resources and results and represents them in terms of constraints for the works implementation programme. The logic according to which the entire system is developed is such that any alteration to the decisions made before may only occur by retracing the process, or rather by altering the previous decision-making phases and obtaining reapproval at the relevant offices. The designer in charge develops the 'Technical and Economic Feasibility Design', according to the 
contents of the 'Guidance Design Document' (Article 23, subsection 5 [1]). In order to ensure the design unit, the competent professionals, before approval, verify the compliance of the 'Detailed' or 'Final' Design respectively, to the 'Final Design' or to the 'Technical and Economic Feasibility Design' (Article 26, subsection 3 [1]).

A sequence thus determined establishes a necessary interdependence between each level, of which the previous levels represent the basis and input for subsequent ones, but on which they can depend in terms of feed-back arising from the need for a review of the inputs provided by the results of the previous phases.

The 'Guidance Design Document', summarizing the contents of the 'Requirements Framework', specifying them, systematizing them and making them binding, directs the subsequent works implementation phases and is configured as a guiding tool that transfers the requests of the client to the building process operators.

Each level of technical detail in the design is the result of a prior level of refinement which is also the first element of comparison to verify their informative contents.

In this vision, the 'Requirements Framework' and the 'Guidance Design Document', programming products that fall under the remit of the Administration, amount to the preparatory documents for the subsequent Design phase.

\section{DESIGN ALTERNATIVES}

Public Works are carried out on the basis of a Three-year Program and annual updates that the Administrations approve together with the Annual List of works to be launched in the first year.

The three-year Program, prepared by the Manager responsible for Planning, summarizes and coordinates building interventions aimed at satisfying previous and future needs, as well as any requests for planning "adjustment" that may come from works previously started and under construction.

In order to drawing up the Three-year Program [4], the Law provides that, for each intervention, in compliance with the contents of 'Requirements Framework' and the 'Guidance Design Document', the Feasibility Design Alternatives Document (Article 3, subsection 1 [5]) is drafted and approved.

This latter, through evaluations of a technical and territorial, economic and financial, and administrative and managerial nature, reflects and justifies the interest, investment and planning of the Public Administration, becoming a fundamental element in the decision-making process.

The feasibility assessments, an integral parts of the initiatives rollout process and the essences of the Three-year Programme that motivate the technical policy of the organization, understood as a process of identifying and defining opportunities, represent also a logical act strictly concerning the 'Requirements Framework' - its essential input condition - which, by using parameters that strictly depend on it to identify and quantify the works instrumental to satisfy the requirements, represent the key tool to support the decision-making operators for the rational, efficient and economically sustainable management of the public investments. 
The 'Feasibility Design Alternatives Document' identifies the type of intervention, checks its geographical location, the environmental and landscape compatibility, the typological, technological and plant solutions, the dimensioning compared to the requirement, the quantification of the resources, the implementation methods, compliance with regulations, the relationship with the infrastructures, the economic and temporal weight, and, through formalizations to different degrees of connotation and intensity, calibrated depending on the specificity of the contexts, it presents a range of alternatives with which the initiative can be implemented, examining also, in order to allow an effective comparative comparison, the hypothesis of non-realization.

The findings of it, aimed at avoiding/reducing the risks of failure and ensuring the safe viability, form the basis for the configuration of a list of achievable and fundable works that the Administration proposes to bring to completion.

\section{DESIGN LEVELS}

The Design phase is broken down into three steps of subsequent levels of technical detail, Technical and Economic Feasibility Design; Final Design and Detailed Design; specific informative contents are attributed to each.

The 'Technical and Economic Feasibility Design' (Article 23, subsections 5 and 6 [1], modified by Ministerial Decree 56/2017 [2]), on the basis of the formalizations contained in the 'Feasibility Design Alternatives Document' and with reference to the 'Requirements Framework', identifies the solution that raises the best cost-benefit ratio for the community and the environment, specifying, compliance with the provisions of the 'Guidance Design Document', performance, dimensional, typological and economic characteristics; functional specifications and requirements for environmental impact mitigation.

The 'Final Design' (Article 23, subsections 7 [1], modified by Ministerial Decree $56 / 2017$ [2]), by fully identifying the work to be carried out and defining the definitive spending limit, consistently with the outcomes of the 'Technical and Economic Feasibility Design' and in compliance with the preparatory documents for Design, clearly defines all the characteristics necessary for the acquisition of opinions, approvals and authorizations required to obtain the 'Building Permit' that is the Administrative provision, issued by the Municipal Authority, that enables the building construction according to the urban planning instruments and the building and sanitary regulations (Presidential Decree 380/2001 [6])

The 'Detailed Design (Article 23, subsection 8 [1]), drawn up according to the Final, specifying in detail each element in formal, typological, qualitative, dimensional and economic terms, represents the so-called "engineering design processes" of the works.

The rules of Public Works contracts ascribe the concept of "cantierabilità" (the set of requirements for a public work to be started), to the 'Detailed Design' so as to clearly explain that "unequivocal" and "comprehensive" set of information and instructions for the start and management of the operational phase. The standard states that the "Detailed Design' < < only excludes the site operational plans, the supply plans, as well as the calculations and the graphics relative to the temporary works $\gg>$ carried out by the company based on the contents of the 'Detailed Design' that ensure greater reliability and completeness. Therefore, there is an intermediate step in which the instructions 
deriving from the previous phase are translated into operational plans aimed at organizing the construction activities and directing the works. This action is the only level of the project that falls under the remit of the company and, in as much, is governed by a contract with the commissioning party which binds it to exclusively represent, without the possibility of altering them, the instructions of the 'Detailed Design' in terms of operational instructions for the executors (Article 26, subsection 1 [5]).

This design level therefore represents the essential basic condition, necessary to ensure the viability of the construction of the works.

The Design, place of transposition and synthesis of environmental, functional, technological and economic choices that contribute to satisfying the needs outlined in the 'Requirements Framework', starting from the preliminary feasibility assessments that arise from the Planning, produces a 'Detailed Design' that represents the object unequivocally and elaborates indications for the procurement methods, for the realization and for the management of the work. In fact, the 'Detailed Design' is also accompanied by a document that plans and programs the building maintenance activity in order to preserve its functionality, quality, efficiency and economic value in its life cycle (Article 23, subsection 8 [1]).

The Design phase is therefore configured as an organized set of information, characterized by the specific intent to communicate certain and precise instructions to all the operators involved in the execution and, as a result of this connotation, represents the link that, within the works implementation process, allows to move from the Planning phase to the Construction phase.

With reference to this segment, the Discipline draws a significant moment, identifiable in the procedures for the Verification, Validation and Approval of the design levels (Article 26 [1]), which "certify" the compliance with the program data, as well as the reliability with regard to the subsequent Construction phase.

\section{CONCLUSION}

The Planning phase, as regards the determination of the 'Guidance Design Document' and the 'Feasibility Design Alternatives Document', aimed at ensuring the work is achievable, represents the most critical moment of the process.

The findings of it mainly interfere with the development of the 'Technical and Economic Feasibility Design' which, in order to adhere to the contents of the standard, must apply the recommendations of the previous refinements and, on the basis of further in-depth studies, transfer them to the subsequent ones, thus risking determining faults in the works implementation processes.

The systems used to prepare the programming instruments therefore, significantly influence the quality of the works.

It is also important to highlight the double connotation that the implementation processes assume due to the effect of the impact on them generated by the combination of the regulatory determinations and the distinctive characteristics that distinguish the building process. Coexist in fact a "linear" concept under which the initial decision must lead to the subsequent ones, an axiom on the basis of which building process 
models are still essentially founded, next to a "circular" feedback system which can lead to feedback on what has already been decided and constitute the characteristic attribution of each "operational" explanation of the works.

For the purposes of optimizing the operating practices, it would be advisable to combine, above all given the constant increase in the complexity of contemporary scenarios, the requirements imposed by the twofold declination.

As a strategic action concerning the performance of the construction sector, aimed at generating value, innovation and growth and reducing errors and waste, the Law promotes the progressive use of specific electronic and informative modeling tools that, using interoperable platforms by means of open formats, allow the digital management of the design informative contents (Article 23 subsection 13 [1]; Ministerial Decree $560 / 2017$ [3]), favoring the increase of the efficiency and organization levels of the
Contracting Administrations.

A further critical scenario factors primarily converge precisely in the weakness of the Public Client in terms of skills, moreover associated with the restrictions on available (herutiny.

To encourage qualification of the Administration decision-making capacity in the management of public demand, helps the selection and qualification of the most profitability. Moreover, offer operators that could, in turn, be advantaged in terms of collaboration between heterogen to the accentuated requirements for coordination and implies, in which integration disciplines that the complexity of scenarios mitigate the risks of extending collaborative terms is crucial, it also contributes to (both the initial construction costs andractual times and exceeding the estimated costs optimizing public investment.

With reference to the critical moment of the process, previously reported, this strategic / management approach, operates from the logic of guiding informed decisions on feasibility check, through more alternate scenarios that can be envisaged, essential for the sharing and the prior identification of the enhancing their potential and advantages problems, allow to control them ex-ante, implementation.

\section{REFERENCES}

[1] Law n. 50, $18^{\text {th }}$ April 2016, Implementation of directives 2014/23/EU, 2014/24/EU and 2014/25 / EU on the awarding of concession contracts and on public procurement, contracts, services and Supplement n. 10, in force since 4.19.2016 Journal n. 91, $19^{\text {th }}$ April 2016, Ordinary

[2] Law n. 56, 19th April 2017, Supplementary and corrective provisions to the Law $50 / 2016$ [1], Official Journal n. 103, $5^{\text {th }}$ May 2017, in force since 5.20.2017 
[3] Decree of the Minister for Infrastructure and Transport n. 560, $1^{\text {st }}$ December 2017, concerning the use of modeling methods and tools in Public Works, published on the Minister website the $12^{\text {th }}$ January 2018 , in force since 1.27 .2018

[4] Decree of the Minister for Infrastructure and Transport, n. 14, 16 ${ }^{\text {th }}$ January 2018, Regulations containing procedures and standard schemes for the preparation and publication of the Three-year Public Works Program, the related Annual Lists and annual updates, Official Journal n. 57, $2^{\text {nd }}$ March 2018, in force since 3.17.2018

[5] Decree of the Minister for Infrastructure and Transport amending Definition of the three design levels informative contents according to article 23, subsection 3, Law 50/2018 [1], Draft May 2018

[6] Presidential Decree n. 380, 6th June 2001, single text of the laws and regulations on building 